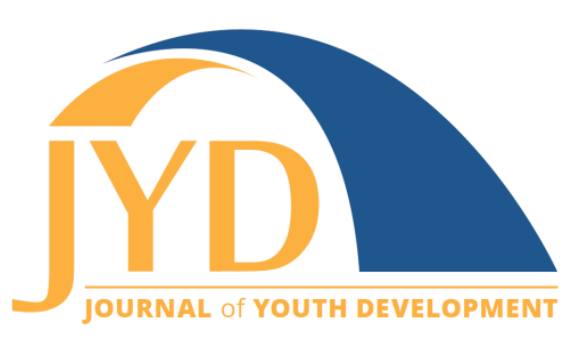

http://jyd. pitt. edu/ | Vol. 13 Issue 4 DOI 10.5195/jyd.2018.644 | ISSN 2325-4017 (online)

\title{
More Than Self-Management: Positive Youth Development at an Inclusive Type 1 Diabetic Camp
}

\author{
Theresa Beesley \\ McGill University, Faculty of Medicine \\ theresa.beesley@mcgill.ca \\ Michael C. Riddell \\ York University, School of Kinesiology and Health Science \\ mriddell@yorku.ca
}

\section{Jessica Fraser-Thomas}

York University, School of Kinesiology and Health Science

jit@yorku.ca

\begin{abstract}
Diabetes-focused camps emerged as a way to provide ongoing diabetes self-management education to youth and their families in a physically active context. Past research suggests participation at camp can enhance youths' glycemic control and glucose monitoring abilities; however, recent studies claim camps can also offer psychological and social benefits. Drawing upon a positive youth development (PYD) approach, the current study examined an inclusive diabetic-focused youth sport camp to (a) identify life skills developed, and (b) explain processes and factors involved in youths' development of life skills. Focus groups were conducted with 54 youth living with type 1 diabetes mellitus (T1DM) attending an inclusive T1DM sport camp. The model of PYD through sport (Holt et al., 2017) guided the analysis. PYD outcomes (i.e., life skills developed through the camp) were (a) enhanced self-efficacy for self-monitoring of blood glucose, (b) enhanced self-efficacy for sport while living with T1DM, and (c) development of positive relationships. These outcomes were facilitated through the camp's inclusive approach (i.e., including youth living with and without T1DM), and a PYD climate (implicitly), which included supportive relationships with counsellors and peers, and interestingly, the lack of parental involvement at the camp. The camp's explicit life skills program focus (i.e., on diabetes self-care skills) also facilitated these outcomes. This study gives camp professionals insight into how an inclusive T1DM sport camp can facilitate life skills, and optimize PYD.
\end{abstract}

Key words: positive youth development, type 1 diabetes mellitus, sport camp, youth chronic disease

(c) $\mathrm{EY}$ New articles in this journal are licensed under a Creative Commons Attribution 4.0 License. This journal is published by the University Library System, University of Pittsburgh and is cosponsored by the University of Pittsburgh Press. The Journal of Youth Development is the official peer-reviewed publication of the National Association of Extension 4-H Agents and the National AfterSchool Association. 


\section{Background}

Worldwide it is estimated that over 542,000 children under the age of 15 are living with type 1 diabetes mellitus (T1DM), and 107,300 of these children live in North America (International Diabetes Federation, 2015). T1DM is an autoimmune disease resulting in a chronic condition where the pancreas does not produce enough insulin for the body (Hanas, 2010). T1DM affects the heart, blood vessels, nerves, eyes, and kidneys, and poor blood glucose management can lead to numerous complications (Hanas, 2010). T1DM also encroaches on youths' personal and psychological development (Guthrie, Bartsocas, Jarosz-Chabot, \& Konstantinova, 2003). Living with T1DM is associated with increased desire for peer acceptance, poor school performance, employment difficulties, increased risk of negative psychosocial outcomes, delays in independence development, and increased prevalence of depression (Delamater, de Wit, McDarby, Malik, \& Acerini, 2014; Kakleas, Kandyla, Karayianni, \& Karavanaki, 2009; Karlsson, Arman \& Wikbald, 2008). Youth living with T1DM suggest they feel different from their peers, and desire being "normal" living without disease (Guthrie et al., 2003).

Diabetes-focused camps were developed to provide youth and their families an alternative educational program for diabetes self-management (John, 1946). Past research has examined youths' self-management (i.e., glycemic control and glucose monitoring) (Nabhan, Rardin, Meier, Eugste \& DiMeglio, 2006) and psychosocial outcomes (Bultas, Schmuke, Moran, \& Taylor, 2015); findings indicate camps can increase youths' knowledge about disease management, nutrition, coping skills, social relationships and anxiety reduction (Santiprabhob et al., 2008). Despite the growing body of research exploring physiological, psychological and social outcomes associated with youth participation in T1DM camps, there remains little understanding of the processes that contribute to these outcomes (De Loach, 2009).

Past research of youth living with T1DM has been framed within a deficit-reduction paradigm, driven by the assumption that youth with T1DM are disadvantaged as a result of their disease, and need interventions to "fix" their psychological or social developmental deficits (Guthrie, et al., 2003; Kakleas, et al, 2009). In contrast, positive youth development (PYD) offers a strength-based approach to exploring development, which views youth as "resources to be developed" rather than "problems to be fixed" (Lerner, Almerigi, Theokas, \& Lerner, 2005). In sport contexts, the PYD lens has been widely used to study youths' personal, psychosocial development. Specifically, research has focused on identifying outcomes of sport participation, and processes in the environment that may be facilitating these outcomes (Holt et al., 2017). 
Recent research suggests participation in sport and physical activity can enhance well-being among youth living with T1DM (Edmunds, Roche, Stratton, Wallymahmed, \& Glenn, 2007). Holt and colleagues' (2017) model of PYD through sport, developed following a meta-review of 63 studies, offers a framework for understanding the processes by which sport may foster positive outcomes. The model proposes sport programs are a microsystem (García Bengoechea, 2002) influenced by broader and more distal ecological systems (Lerner, Bowers, Geldhof, Gestsdóttir, \& DeSouza, 2012). Within this microsystem, youths' relationships with adults, positive interactions with peers, and parental supportive behaviours create a PYD climate, "a social environment that enables youth to gain experiences that will contribute to PYD outcomes" (Holt et al., 2017, p.32). The PYD climate can facilitate PYD through implicit processes alone (i.e., through strong relationships between youth, adult leaders, and peers); however, it is hypothesized that explicit processes (i.e., specific pedagogical strategies to teach life skills) can further enhance PYD outcomes (Holt et al., 2017). This model serves as an appropriate lens of examination for the study - given its focus on practical program delivery and our focus on identifying PYD outcomes-and understanding processes facilitating these outcomes.

\section{Rationale and Purpose}

Current research suggests participation in diabetes camps leads to youths' effective selfmanagement of their diabetes (Nabhan, et al., 2006) and development of life skills (Bultas et al., 2015). However, there remains little understanding of the processes that contribute to life skills development in a diabetes camp context (De Loach, 2009). As such, Bialeschki, Henderson, and James (2007) called for further research examining factors within camps that may be contributing to theses beneficial outcomes. We were interested in studying a diabetes camp with a sport focus, given extensive research highlighting the role of sport in facilitating PYD, and the promotion of sport as a positive lifestyle context for diabetic youth to enhance well-being (Edmunds et al., 2007). Further, we chose to study youths' experiences in an inclusive camp given Maslow and Lobato's (2009) concern that previous research has been conducted primarily in "diabetic only" environments. Additionally, an inclusive camp provided a setting similar to that of youths' daily lives, where diabetic youth engage in activities alongside their non-diabetic peers. Thus, this study addressed limitations and gaps of past work, by examining an inclusive diabetes-focused youth sport camp, and specifically (a) identifying life skills developed through the camp, and (b) explaining processes and factors involved in youths' development of life skills. The PYD through sport model (Holt et al., 2017) offered a framework for exploring the climate, activities, and outcomes of life skills development within the diabetes sports camp. 


\section{Methods}

\section{Camp Context}

The sport (day) camp selected for this study was established in 2008, at a large university in Toronto, Canada. The camp identified as an "inclusive diabetes camp" meaning it welcomed youth living with and without T1DM. At the time of data collection (2011), a variety of industry partners and charitable organizations provided financial support for the camp's administration and operation costs, and for all medical T1DM monitoring devices.

The camp offered 1-week or 2-week programs, with four sport options: soccer, tennis, basketball, and track and field. The primary focus of the camp was the development of sport skills, with a secondary goal of teaching diabetes self-management while being physically active. This approach is unique to this particular diabetes-focused camp, given most camps place precedence on diabetes self-management over other camp-related activities (McAuliffeFogarty, Ramsing \& Hill, 2007).

The camp staff included nurses and camp counsellors. Nurses provided medical care and glucose monitoring for the campers living with T1DM and diabetes management training for camp counsellors. An inclusive approach was used to hire camp staff; counsellors included young adults living with T1DM involved in sport, and (non-diabetic) varsity athletes who attended the university. A minimum of two camp counsellors living with T1DM were assigned to each sport stream provided by the camp. All counsellors were required to complete the standard health and safety and diabetes care training seminars before the camp began.

\section{Participants and Procedure}

Approximately 110 youth participated in the camp over the two-week study period, including 61 youth living with T1DM. Of the 61 youth with T1DM, 54 chose to participate in the study. Study participants were ages 8 to 16 , with males representing $63 \%(n=34)$ of the sample, and average years living with diabetes being $4(S D=2.17)$. Data were collected during both weeks of the camp, with approximately $40 \%$ of participants enrolled in only 1 week. Before the start of the camp each week, youths' parents were provided information packages and completed consent forms approved by the university's ethics committee. This study was part of a larger project that examined the effectiveness of using constant glucose monitoring among campers living with T1DM (see Riddell \& Milliken, 2011). 


\section{Data Collection}

Nine mixed-sex focus groups of three to nine participants were conducted, organized practically around the sport in which the youth were enrolled. Discussions followed a semi-structured interview guide (Krueger \& Casey, 2009) developed based on previous PYD-sport research (Camiré, Forneris, Trudel \& Bernard, 2011; Fraser-Thomas, Côté, \& Deakin, 2005; Petitpas, Cornelius, Van Raalte \& Jones, 2005). Specifically, given past PYD research suggesting adult leaders play an integral role in the process of life skills development, interview guides focused on exploring the roles of these individuals; probes related to the environment, facilitators, life skills developed, and specific sport contexts. Additionally, youth were probed on how the camp may have impacted their development of life skills. All focus group interviews were conducted by the primary researcher at the end of the camp session (i.e., last day or second last day the youth attended the camp), and recorded on a digital recorder.

\section{Data Analysis}

An inductive-deductive content analysis approach was used (Hsieh \& Shannon, 2005), whereby codes emerging from the data were organized according to existing theory. Two research assistants transcribed focus group recordings verbatim; the primary researcher repeatedly read the transcripts for accuracy, and to establish broad understanding of the data (Tesch, 1990). Next, codes were identified; codes have been described as meaningful pieces of information that represent ideas, concepts, terms or phrases that emerged from the transcripts (Tesch, 1990). Codes were then organized in categories according to similar meaning (Corbin \& Strauss, 1988; Strauss \& Corbin, 1990). During the deductive analysis phase, categories identified during inductive analysis were further considered for fit, similarities, and differences within the four key constructs of Holt and colleagues' (2017) model of PYD (i.e., PYD outcomes, distal ecological systems, PYD climate, and life skills program focus; see Table 1); however, some categories within the distal ecological systems construct (e.g., camp and funders' philosophies) fell outside the key aims of the study and are presented elsewhere (Beesley, Fraser-Thomas, \& Riddell, 2013). Throughout both the inductive and deductive analysis, concerns and discrepancies were discussed between the primary and secondary researcher until complete agreement was reached. Pseudonyms were used throughout. 


\section{Results}

This study examined an inclusive diabetic youth sport camp, with the aim of (a) identifying life skills developed among youth in the camp, and (b) explaining the processes and factors facilitating youths' development of these life skills. Results are reported in line with the four main interconnected components of Holt and colleagues' (2017) PYD through sport model: PYD outcomes, distal ecological systems, PYD climate, and life skills program focus.

Table 1: Themes Reported in the Holt and Colleagues' (2017) PYD Through Sport Model

\begin{tabular}{|l|l|}
\hline \multirow{2}{*}{ Model } & Theme \\
\hline \multirow{3}{*}{ PYD outcomes } & Enhanced self-efficacy for self-monitoring of blood glucose \\
\hline & Enhanced self-efficacy for sport while living with T1DM \\
\hline \multirow{2}{*}{ PYD climate } & Development of positive relationships \\
\hline \multirow{3}{*}{ PYD program focus } & Camp's inclusive approach \\
\hline & Counsellor relationships \\
\hline & Peer relationships \\
\hline & Parental (lack of) involvement \\
\hline & Parent-child conversations \\
\hline & Safe and supportive environment \\
\hline & Safe sport environment \\
\hline & Self-monitoring strategies \\
\hline
\end{tabular}

\section{PYD Outcomes}

Findings suggest three key PYD outcomes: (a) enhanced self-efficacy for self-monitoring of blood glucose, (b) enhanced self-efficacy for sport while living with T1DM, and (c) development of positive relationships. First, youth described experiences of dealing with the highs and lows of blood glucose, carbohydrate counting, and self-maintenance of normal blood glucose, and how this gave them a sense of enhanced self-efficacy for self-management of diabetes. Second, 
PYD at an Inclusive Diabetes Sport Camp

youths' experiences of enhanced self-efficacy for sport were discussed in relation to their increased belief in their ability to be physically active, increased social comfort testing blood glucose in public sport settings, and ability to engage in constant glucose monitor reinsertion (e.g., when monitors became loose or fell out). Third, youth discussed how their time in the camp provided opportunities for them to make new friends living with and without T1DM and to improve their communication skills through opportunities to speak to others about T1DM and diabetes management.

\section{Distal Ecological Systems}

A key distal influence at the organizational level was the camp's inclusive approach, whereby non-diabetic and youth living with T1DM both participated at the camp. This approach facilitated several developmental opportunities related to youths' self-efficacy for selfmanagement of diabetes and participation in sport, as well as youths' social inclusivity. For example, several youth described changing comfort levels in testing their glucose levels: "The camp has helped me test in front of people, because before I felt nervous to do it, but now I can do it in front of all people." This was in contrast to experiences in other sport programs where campers expressed embarrassment when testing in front of others who were not diabetic. Bailey made one such comparison, "When I was getting ready for hockey [on my team] I went really, really high and I had to stick a needle in, and my whole team was watching me. I really felt on display." Casey also pointed out that the inclusive approach likely enhanced the knowledge and understanding of non-diabetic participants about diabetes, which in turn likely had positive social effects:

I think it's good that other people that don't have diabetes are here. That way they know more about it, and if they ever meet somebody else that has diabetes, they won't be as annoying as the people who don't have any idea of what diabetes is ... and that's good for everyone.

Generally, the inclusive approach appeared to create a more socially inclusive community, by making youth with T1DM more comfortable, and potentially decreasing stigma through enhanced knowledge, and understanding of chronic disease among youths' non-diabetic peers.

\section{PYD Climate}

PYD outcomes were facilitated through implicit processes, whereby the established PYD climate of supportive relationships with counsellors and peers, created a context for campers' personal 
PYD at an Inclusive Diabetes Sport Camp

and social development. Parents' changes in involvement-specifically the decrease in reminders and extensive monitoring of blood glucose level-facilitated camper's development of self-efficacy for monitoring their blood glucose independently.

\section{Counsellor Relationships}

Campers identified that all counsellors (i.e., counsellors living with and without T1MD) created a climate of open communication and discussion about diabetes, while always being available to aid with diabetes management. Additionally, counsellors living with T1DM acted as role models by living physically active lifestyles while effectively managing T1DM. Sarah said, "I like this camp because of the counsellors. ... There are more counsellors with T1DM than any other camp I've been to before. And when they test I remember to test." Counsellors shared experiences about playing sports and managing their blood glucose levels-experiences that campers could relate to-while providing guidance or advice. For example, Michelle said, "I think it's important because they (counsellors living with T1DM) know what it feels like and they can tell you things about their experiences." Consequently, campers often formed very strong relationships with counsellors. Collectively, campers' experiences with counsellors contributed to a PYD climate that implicitly facilitated campers' positive PYD outcomes.

\section{Peer Relationships}

In addition to counsellor relationships, campers also discussed relationships with camp peers. Campers identified two distinct groups of peers: peers living with T1DM and peers living without T1DM, and discussed how both groups facilitated opportunities for social inclusion and positive relationships.

First, as noted above, campers described peers' roles in normalizing the checking of blood glucose, and that this in turn allowed them to fully engage in programming, rather than being told to sit out after checking their blood sugar levels. As Carter explained, "I liked the fact that if you're doing a sport and you have a low blood sugar, it wouldn't be weird if you go out and leave what you're doing to check your sugar, because everyone's doing that." Adam expanded on this point:

Well, it's better to be surrounded by other people who have diabetes because no one is really going to ask any questions. Like sometimes people say (outside the camp), "Why do you have that camera bag?" I'm like, "It's not a camera bag. " And they ask 
PYD at an Inclusive Diabetes Sport Camp

questions. But here it doesn't really matter, because no one is going to ask what that is if they have it too.

Youth outlined how in other sport contexts they often felt "left out" or that they were "missing something," as the rest of their team would move forward, leaving them behind. Russell said, "My soccer coach didn't let me play my second year on the team because I was 'diabetic,' so I was on the bench a lot." However, at this camp, youth consistently emphasized how an openness about testing among diabetic and non-diabetic peers enhanced their self-efficacy for participation in sport. Katie said, "Here everyone doesn't have to stop when I test my blood sugars. Everyone keeps on playing."

Participants also discussed their friendships with youth living with T1DM. This camp offered an opportunity to build friendships based on common interests (i.e., sport), rather than over similar challenges (i.e., living with a chronic disease). Aaron said, "Before at other camps we just talk about diabetes and made crafts. But, here we can do more stuff together." For those recently diagnosed, the benefits were particularly great as they had a chance to meet other diabetics of similar age in a setting that welcomed the disease. Carter explained,

I was depressed about being diagnosed. I just wanted to stay inside all the time, and I never wanted to come out. My mom kept telling me that there were other people that have diabetes but I didn't believe her. When I came to the diabetes camp, I realized there actually are some benefits to it (the camp) because you get to experience new people that have diabetes.

Similarly Sarah said, "It made me realize there are other people that have diabetes that can just handle it-like it's just a daily thing."

Finally, peers also created a climate where their diabetes knowledge and education were enhanced. Specifically, campers (and particularly recently diagnosed campers) felt they were leaving the camp with a better understanding of their disease-in part because of the supportive relationships and established sense of community amongst campers living with T1DM-which promoted communication and sharing of personal experiences. Michelle said, "I think [being at a camp with other youth living with T1DM] is important because they know what it feels like and they can tell you things about their experiences." Campers explained that being in a camp with peers living with and without T1DM provided a context for youth to discuss and talk openly about diabetes among a more diversified peer group, which seemed to be something they would build upon after leaving the camp. 
Overall, peers were an important part of group living at the camp. Campers described that their previous camp and sport experiences with non-diabetic youth were coupled with stigma and lack of knowledge regarding T1DM. Mark said, "At other camps people [living without T1DM] thought I was doing drugs [when using an insulin needle]. They would see the syringe and be like, 'What are you doing?"' Through discussions regarding diabetes among their peers, and the normalization of testing blood glucose in public, campers living with T1DM gained confidence in their abilities to effectively engage in self-management of their diabetes in a physically active environment, and experienced enhanced self-efficacy for sport.

\section{Parental (Lack of) Involvement}

Campers suggested parents' minimal involvement contributed to their development of diabetes self-management skills. For example, Casey made comparisons between this camp and her previous camp experiences:

When I would go to other camps, my mom would be calling me every ten minutes, and she'd show up with like the reddest face and be like, "Oh my God, are you okay? Did you take your insulin?" But, here she's like, "Okay.". . . She's fine.

Youth consistently indicated that at this camp, their parents showed less anxiety regarding their self-monitoring abilities, which in turn made the campers less anxious. As Casey elaborated, "I enjoy not having to worry. My parents would worry, which would kind of lead to me worrying." Parents' decreased concern translated into less parental presence within the camp context (i.e., parents "left [them] alone").

Youth suggested their parents were more trusting of this camp in comparison to other programs, due to the staff members' (i.e., diabetic counsellors and trained nurses) experience, expertise, and training. Jamie said,

Before (starting the camp) my mom wasn't really sure about the camp because she didn'treally know what they were doing (to monitor blood glucose levels). On my second day at the camp she started to trust the camp more, and by the third day when my blood sugar was pretty much fine, she just said, "Do what they tell you and have fun."

Campers described how their parents felt assured that the staff was sufficiently prepared to take care of them if they experienced hypoglycemia. Due to parents' trust and lack of 
PYD at an Inclusive Diabetes Sport Camp

involvement, youth had the rare opportunity to attend and participate in all camp activities, rather than just the most risk-averse activities.

\section{Parent-Child Conversation}

Youth highlighted an interesting consequence of parents' decreased anxiety: a shifted focus of parent-child conversations outside the camp. Rather than discussing glucose levels, parents instead inquired about general events and activities within the campers' day or the new friends that they were making. For many youth, this was a novel experience, paving the way for more engaging and effective communication between themselves and their parents. Jesse said, "When I go to other camps they always ask me when I get home, 'Were you okay?' and stuff. But now they just ask me what happened at camp, instead of asking if I was okay."

\section{PYD Program Focus}

In addition to PYD outcomes facilitated through implicit processes within a PYD climate, outcomes were also facilitated through the camp's explicit focus on developing youths' diabetes self-care skills while being physically active, and drew upon several strategies to do so.

\section{"Safe" Diabetes Environment}

Significant investment was made in the camp staff to create a safe environment. The staff included a team of diverse "experts" in healthcare and glucose-management (i.e., nurses), in sport (i.e., varsity athletes), and in diabetes management while being physically active (i.e., counsellors living with T1DM). This was in contrast to youths' previous camp experiences, where the camp supervisors/leaders did not know how to manage their diabetes, making it difficult for the youth to develop self-management skills. Youth repeatedly emphasized how the trained staff made them feel safe and able to engage in all the activities without worrying about complications with their diabetes. As Aaron said, "I came to this camp because it's more safe and comfortable. You have more trained nurses and everything-you have glucose pills and index charts and stuff."

\section{"Safe" Sport Environment}

Campers also discussed how the camp provided them with opportunities to engage in sport at the intensity of their choice. The opportunity to participate in sport in a safe diabetes 
PYD at an Inclusive Diabetes Sport Camp

environment allowed them to feel more comfortable as they initiated their journey to prediagnosis sport levels. As Sam explained,

Well, before I was diagnosed I was like really athletic. I'd do all

these sports, and then ever since I was diagnosed I've been really

scared to exercise-scared of lows. So, if I came here, I knew that

people would know what to do.

Thus, the security of knowing the staff knew how to manage their blood glucose levels during various sport intensities empowered them to regain their level of pre-diagnosis sport participation.

\section{Self-Monitoring Strategies}

Finally, counsellors played a central role in facilitating youths' self-monitoring strategies.

Campers described the "fun" strategies they used to remind each other to test their blood sugar levels. In one example, they established a secret word (i.e., "chocolate") to remind them to test their blood sugar. Youth recalled that fellow campers, with and without diabetes, would shout the word out after long periods of activity or after meals to remind those who needed to test.

\section{Discussion}

Bialesckhi and colleagues (2007) called for a more rigorous evaluation of the outcomes youth gain from camp experiences. This study utilized a PYD approach, which provided a novel and appropriate lens of inquiry, given the traditionally utilized deficit-reduction approach to explore outcomes at diabetes camps (Lerner et al., 2005). Specifically, Holt et al.'s (2017) model of PYD framed our analysis, allowing for a comprehensive interpretation of the interconnected outcomes and processes of development. Results suggest three key outcomes among youth: (a) enhanced self-efficacy for self-monitoring of blood glucose, (b) enhanced self-efficacy for sport while living with T1DM, and (c) development of positive relationships. The inclusive structural design of the camp (i.e., open to diabetic and non-diabetic youth) facilitated PYD outcomes at a distal ecological systems level. Adult leaders (i.e., nurses, counsellors living with T1DM, varsity athlete counsellors), camp peers (both diabetic and non-diabetic), and parents created a PYD climate that facilitated these PYD outcomes. The camp's explicit approaches, using specific strategies aimed at enhancing youths' self-management of glucose levels while being physically active also facilitated PYD outcomes. 
PYD at an Inclusive Diabetes Sport Camp

This study of an inclusive camp, whereby children without diabetes participated alongside children living with T1DM (i.e., a more naturalistic setting), addressed a void in previous research, given the majority of existing research has been conducted in "diabetic only" environments (Maslow \& Lobato, 2009). While past investigations have focused primarily on identifying improvements in glycemic control (e.g., Santiprabhob et al., 2008), this study identified additional psychosocial outcomes and described the environments facilitating these outcomes.

Findings build upon past camp research illustrating the benefits of having counsellors living with T1DM; they served as valuable knowledge resources and relatable role models, in turn contributing to youths' improved diabetes self-management (Karlsson et al., 2008; Thurber, Scanlin, Scheuler, \& Henderson, 2007). Consistent with past research in sport settings (FraserThomas et al., 2005; Holt et al., 2017), peers were identified as key contributors to youths' PYD, serving as sources of knowledge and positive role models, particularly among those recently diagnosed and those living with their diagnosis for some time. This is consistent with sport team settings, which offer informal opportunities for leadership and role modeling (FraserThomas \& Côté, 2009; Weiss, Stuntz, Bhalla, Bolter, \& Price, 2013). Campers highlighted their opportunity to develop friendships built upon common interests (i.e., sports) rather than a shared disease; they discussed a sense of belonging and community similar to that found in sport and team settings (Strachan \& Davies, 2015; Turnnidge, Vierimaa, \& Côté, 2012).

While Holt and colleagues' (2017) model of PYD through sport highlights parents' active role in contributing to a PYD climate, ironically, in this context, parents' optimal contribution to campers' PYD appeared to be through inactive roles. The camp offered youth freedom from parental oversight during camp hours. Youth perceived less parental anxiety while they were at the camp, which decreased campers' anxiety, in turn increasing their autonomy and enjoyment. Most enlightening was the shift in parent-child interactions to more engaging (non-diabetes) conversations, which accompanied this change. Research has stressed the importance of adaptive relationships within families with chronic health conditions to promote positive psychological adjustment (Drotar, 1997). In our current culture of overprotecting children (Ungar, 2009), these findings should be given particular attention and may serve as a springboard for further intervention studies aiming to gradually decrease parents' anxiety, to in turn enhance youths' PYD outcomes.

Holt and colleagues (2017) hypothesized "the combined effects of a PYD climate and [an explicit] life skills focus will produce more PYD outcomes than a PYD climate alone" (p. 38). This 
PYD at an Inclusive Diabetes Sport Camp

hypothesis is consistent with several claims within the literature that PYD outcomes need to be deliberately taught, rather than simply "caught" through sport participation alone (Gould \& Carson, 2008). However, in this study, it was not always clear if boundaries existed between an optimal PYD climate (i.e., implicit, supportive caring relationships of adults and peers), and the life skills focus of the program (i.e., explicit, pedagogical strategies to facilitate PYD outcomes). Specifically, the caring and trusting relationships that developed between campers, leaders, and peers, were directly tied to the explicit life skills approach of the camp (i.e., promoting glucose self-management).

While we provide evidence in our analysis for the camp's explicit life skills focus, the strategies implemented (e.g., promotion of youths' self-care, provision of supportive qualified staff) were done via the PYD climate. Our reflections are in line with other blurred interpretations of implicit and explicit approaches. For example, Bialeschki and colleagues (2007) suggest that camps are not inherently good without purposeful and directed efforts by the camp professionals. Given leaders' and peers' central role in the delivery of life-skills specific programs, it became unclear throughout our analysis whether the constructs of a PYD climate and a life skills-focused program could indeed be teased apart in this diabetes camp context—or whether an optimal PYD climate simply encompassed various explicit approaches to life skill development. While this consideration may appear circular or irrelevant, we feel further consideration of this point is warranted, to effectively guide practitioners on whether two distinctive constructs should build upon each other to facilitate more PYD outcomes (as Holt and colleagues, 2017 hypothesize), or if the two interconnected constructs are inevitably necessary in order to optimize PYD outcomes.

In sum, this study strengthens our understanding of youths' experiences while attending an inclusive diabetes sport camp and how these experiences may facilitate PYD outcomes; however, study limitations highlight areas for future research. First, this study was limited in that it did not quantitatively examine long-term effects of the camp on youths' selfmanagement. Given past research showing youths' self-management skills and glucose control deteriorate following the end of camp (Santiprabhob et al., 2008), longitudinal research is warranted to explore the maintenance of optimal self-management behaviours following the conclusion of camp, and whether an inclusive approach (and subsequent normalization of glucose monitoring and testing among non-diabetic peers) may promote maintained levels of self-management. 
PYD at an Inclusive Diabetes Sport Camp

Results are also limited in that they capture the experiences of youth in one specific camp setting, at one point in time. Additional research should continue drawing upon Holt and colleagues' (2017) model of PYD through sport, to examine distal ecological systems (i.e., the structural, organizational environment in which the camp takes place) and individuals' differences, and how these factors may influence youths' PYD outcomes. Broadly, organizational missions, philosophies, and camp funders, and more narrowly, individuals' characteristics (i.e., age, gender, ethnicity, socio-economic status), and differences (i.e., traits, dispositions) likely influence PYD outcomes. For example, recently T1DM-diagnosed youth in this study appeared to experience greater benefits from the camp, as they engaged for the first time with others living and successfully coping with T1DM. This is important given research showing poor adjustment through this initial phase can increase children's risk for psychological difficulties later in life (Northam, Matthews, Anderson, Cameron, \& Werther, 2005). As such, future research on organizational and individual differences may be particularly relevant for programmers moving forward.

Finally, it is important to continue identifying the psychosocial outcomes associated with camp experiences for youth living with chronic disease, rather than focusing exclusively on physiological outcomes. Youth living with T1DM are often bullied and feel like outsiders within their daily life contexts, as they may not have met other youth living with their disease (Peters, Storch, Geffken, Heidgerken, \& Silverstein, 2008). The results of this study provide additional rationale for the importance of shared lived experiences amongst T1DM youth, optimized by the T1DM camp context. Future research is needed to continue to identify the specific components of the camp that contribute to the psychological and social development among youth living with chronic disease, to in turn enhance their overall health and well-being. The application of this study's findings on camp program development and design should be considered on a case by case basis, as optimal approaches vary depending on extensive factors including individuals' abilities, needs, and social situation (Goodwin \& Watkinson, 2000; Spencer-Cavaliere, 2017).

\section{Acknowledgements}

The authors wish to acknowledge York University Faculty of Health, York Sports and Recreation, Medtronic Diabetes Canada, and I Challenge Diabetes. 


\section{References}

Beesley, T., Fraser-Thomas, J. \& Riddell, M. (2013). S'more than just a camp: Exploring the psychosocial skills development of youth attending a type 1 diabetes sports camp. Paper presented at the 2008 North American Society for the Psychology of Sport and Physical Activity Conference, Niagara Falls, Canada. Abstract retrieved from https://journals.humankinetics.com/doi/pdf/10.1123/jsep.35.s1.s75

Bialeschki, M. D., Henderson, K. A., \& James, P. A. (2007). Camp experiences and developmentaloutcomes for youth. Child and Adolescent Psychiatric Clinics of North America, 16(4), 769-788. doi:10.1016/j.chc.2007.05.011

Bultas, M. W., Schmuke, A. D., Moran, V., \& Taylor, J. (2015). Psychosocial outcomes of participating in pediatric diabetes camp. Public Health Nursing, 33(4), 295-302. doi:10.1111/phn.12218

Camiré, M., Forneris, T., Trudel, P., \& Bernard, D. (2011). Strategies for helping coaches facilitate positive youth development through sport. Journal of Sport Psychology in Action, 2(2), 92-99. doi:10.1080/21520704.2011.584246

Corbin, R. N., \& Strauss, A. (1988). Grounded theory research: Procedures, canons, and evaluative criteria. Qualitative Sociology, 13(1), 3-21. doi:10.1007/BF00988593

Delamater, A. M., de Wit, M., McDarby, V., Malik, J., \& Acerini, C. L. (2014). Psychological care of children and adolescents with type 1 diabetes. Pediatric Diabetes, 15, 232-244. doi:10.1111/pedi.12191

De Loach, S. (2009). A pilot study to stabilize normoglycemia during an educational camp for children and adolescents with type 1 diabetes mellitus. Insulin, 4(3), 158-168. doi:10.1016/S15570843(09)80030-4

Drotar, D. (1997). Relating parent and family functioning to the psychological adjustment of children with chronic health conditions: What have we learned? What do we need to know? Journal of Pediatric Psychology, 22(2), 149-165.

Edmunds, S., Roche, D. M., Stratton, G., Wallymahmed, A. K., \& Glenn, S. M. (2007). Physical activity and psychological well-being in children with type 1 diabetes. Psychology, Health and Medicine, $12(3), 353-363$.

Fraser-Thomas, J. L., Côté, J., \& Deakin, J. (2005). Youth sport programs: An avenue to foster positive youth development. Physical Education and Sport Pedagogy, 10, 19-40. doi:10.1080/1740898042000334890

Fraser-Thomas, J. L., \& Côté, J. (2009). Understanding adolescents' positive and negative developmental experiences in sport. The Sport Psychologist, 23, 3-23. doi:10.1123/tsp.23.1.3

García Bengoechea, E. (2002). Integrating knowledge and expanding horizons in developmental sport psychology: A'bioecological perspective. Quest, 54(1), 1-20. 
Journal of Youth Development | http://jyd.pitt.edu/ | Vol. 13 Issue 4 DOI 10.5195/jyd.2018.644

PYD at an Inclusive Diabetes Sport Camp

Goodwin, D. L., \& Watkinson, E. J. (2000). Inclusive physical education from the perspective of students with physical disabilities. Adapted Physical Activity Quarterly, 172), 144-160. doi:10.1123/apaq.17.2.144

Gould, D., \& Carson, S. (2008). Life skills development through sport: Current status and future directions. International Review of Sport and Exercise Psychology, 1(1), 58-78. doi:10.1080/17509840701834573

Guthrie, D. W., Bartsocas, C., Jarosz-Chabot P., \& Konstantinova, M. (2003). Psychosocial issues for children and adolescents with diabetes: Overview and recommendations. Diabetes Spectrum, 16(1), 7-12. doi:10.2337/diaspect.16.1.7

Hanas, R. (2010). Type 1 Diabetes in Children and Adolescents. London, UK: Class Publishing, Barb House, Barb Mews.

Holt, N. L., Neely, K. C., Slater, L. G., Camiré, M., Côté, J., Fraser-Thomas, J., MacDonald, D., Strachan, L., \& Tamminen, K. A. (2017). A grounded theory of positive youth development through sport based on results from a qualitative meta-study. International Review of Sport and Exercise Psychology, 10(1), 1-49. doi:10.1080/1750984X.2016.1180704

Hsieh, H. F., \& Shannon, S. E. (2005). Three approaches to qualitative content analysis. Qualitative Health Research, 15(9), 1277-1288. doi:10.1177/1049732305276687

International Diabetes Federation (2015). IDF Diabetes Atlas. Seventh Edition

John, H. J. (1946). The planning of a camp for diabetic children. American Journal of Medicine, 1, 642648.

Kakleas, K., Kandyla, B., Karayianni, C., \& Karavanaki, K. (2009). Psychosocial problems in adolescents with type1 diabetes mellitus. Diabetes and Metabolism, 35, 339-350. doi:10.1016/j.diabet.2009.05.002

Karlsson, A., Arman, M., \& Wikbald, K. (2008). Teenagers with type 1 diabetes a phenomenological study of the transition towards autonomy in self-management. International Journal of Nursing Studies, 45, pp. 562-570. doi:10.1016/j.ijnurstu.2006.08.022

Krueger, R. A., \& Casey, M. A. (2009). Focus groups: A practical guide for applied research (4 $4^{\text {th }}$ ed). Thousand Oaks, CA: SAGE.

Lerner, R. M., Almerigi, J. B., Theokas, C., \& Lerner, J. V. (2005). Positive youth development: A view of the issues. Journal of Early Adolescence, 25(1), 10-16. doi:10.1177/0272431604273211

Lerner, R. M., Bowers, E. P., Geldhof, G. J., Gestsdóttir, S., \& DeSouza, L. (2012). Promoting positive youth development in the face contextual changes and challenges: The roles of individual strength and ecological assets. New Directions for Youth Development, 135, 119-128. doi:10.1002/yd.20034

Maslow, G. R., \& Lobato, D. (2009). Diabetes summer camps: History, safety and outcomes. Pediatric Diabetes, 10, 278-288. doi:10.1111/j.1399-5448.2008.00467.x 
McAuliffe-Fogarty, A. H., Ramsing, R., \& Hill, E. (2007). Medical specialty camps for youth with diabetes. Child and Adolescent Psychiatric Clinics of North America, 16, 887-908. doi:10.1016/j.chc.2007.05.006

Nabhan, Z. M., Rardin, L., Meier, J. Eugste, E. A., \& DiMeglio, L. A. (2006). Predictors of glycemic control on insulin pump therapy in children and adolescents with type 1 diabetes. Diabetes Research and Clinical Practice, 74(3), 217-221. doi:10.1016/j.diabres.2006.03.020

Northam, E. A., Matthews, L. K., Anderson, P. J., Cameron, F. J., \& Werther, G. A. (2005). Psychiatric morbidity and health outcome in Type 1 diabetes-perspectives from a prospective longitudinal study. Diabetic Medicine, 22(2), 152-157. doi:10.1111/j.1464-5491.2004.01370.x

Peters, C. D., Storch, E. A., Geffken, G. R., Heidgerken, A. D., \& Silverstein, J. H. (2008). Victimization of youth with type-1 diabetes by teachers: relations with adherence and metabolic control. Journal of Child Health Care, 12(3), 209-220. doi:10.1177/1367493508092508

Petitpas, A., Cornelius, A., Van Raalte, J., \& Jones, T. (2005). A framework for planning youth sport programs that foster psychosocial development. The Sport Psychologist, 19(1), 63-80. doi:10.1123/tsp.19.1.63

Riddell, M. C., \& Milliken, J. (2011). Preventing exercise induced hypoglycemia in type 1 diabetes using real-time continuous glucose monitoring and a new carbohydrate intake algorithm: An observational field study. Diabetes Technology and Therapeutics, 13(8), 819-825. doi:10.1089/dia.2011.0052

Santiprabhob, J., Likitmaskul, S., Kiattisakthavee, P., Weerakulwattana, P., Chaichanwattanakul, K., Nakavachara, P., Peerapatdit, T. \& Nitiyanant, W. (2008). Glycemic control and the psychological benefits gained by patients with type 1 diabetes mellitus attending the diabetes camp. Parent Education and Counseling, 73, 60-66. doi:10.1016/j.pec.2008.05.023

Spencer-Cavaliere, N. (2017). Inclusion in the Field(s) of Dreams? In Sport Canada Research Initiative Conference 2017 Knowledge Translation Papers. Retrieved from http://sirc.ca/sites/default/files/content/scri_2017_kt_papers.pdf

Strachan, L., \& Davies, K. (2015). Click! Using photo elicitation to explore youth experiences and positive youth development in sport. Qualitative Research in Sport, Exercise and Health, 7, 170191. doi:10.1080/2159676X.2013.867410

Strauss, A., \& Corbin, J. M. (1990). Basics of qualitative research: Grounded theory procedures and techniques. Thousand Oaks, CA: Sage.

Tesch, R. (1990). Qualitative research: Analysis types and software tools. New York, NY: Routledge.

Thurber, C. A., Scanlin, M. M., Scheuler, L., \& Henderson, K. A. (2007). Youth development outcomes of the camp experience: Evidence for multidimensional growth. Journal of Youth and Adolescence, 36(3), 241-254. doi:10.1007/s10964-006-9142-6 
Journal of Youth Development | http://jyd.pitt.edu/ | Vol. 13 Issue 4 DOI 10.5195/jyd.2018.644

PYD at an Inclusive Diabetes Sport Camp

Turnnidge, J., Vierimaa, M., \& Côté, J. (2012). An in-depth investigation of a model sport program for athletes with a physical disability. Psychology, 3(12A), 1131-1141.

doi:10.4236/psych.2012.312A167

Ungar, M. (2009). Overprotective parenting: Helping parents provide children the right amount of risk and responsibility. The American Journal of Family Therapy, 373), 258-271. doi:10.1080/01926180802534247

Weiss, M. R., Stuntz, C. P., Bhalla, J. A., Bolter, N. D., \& Price, M. S. (2013). 'More than a game': Impact of The First Tee life skills programme on positive youth development: Project introduction and Year 1 findings. Qualitative Research in Sport, Exercise and Health, 5(2), 214-244. doi:10.1080/2159676X.2012.712997 